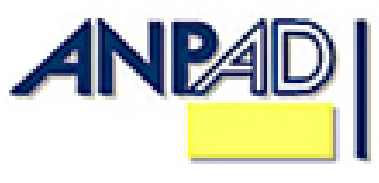

Available online at http://www.anpad.org.br/bar

BAR, Rio de Janeiro, v. 12, n. 1, art. 5, pp. 88-108, Jan./Mar. 2015

\title{
The Effects of Trust Transference, Mobile Attributes and Enjoyment on Mobile Trust
}

Cristiane Junqueira Giovannini Pontifícia Universidade Católica do Rio de Janeiro - PUC-Rio/IAG

Jorge Brantes Ferreira Pontifícia Universidade Católica do Rio de Janeiro - PUC-Rio/IAG

Jorge Ferreira da Silva Pontifícia Universidade Católica do Rio de Janeiro - PUC-Rio/IAG

Daniel Brantes Ferreira Ibmec Rio de Janeiro

Received 22 August 2014; received in revised form 15 February 2015 (this paper has been with the authors for two revisions); accepted 15 February 2015; published online 17 March 2015. Editor's note. Delane Botelho served as Action Editor for this article. 


\begin{abstract}
Trust is essential in building relationships. In mobile commerce, as in electronic commerce, trust is even more valuable given the absence of human contact and direct observation of the service provider. Despite the importance of trust for mobile commerce, there has been little academic effort to study the relationships between mobile devices unique components of interactivity and customer trust, or the relationship between offline, online and mobile trust. This study proposes a trust-mediated model for customer attitude and transaction intentions in mobile commerce contexts that incorporates trust transference and unique factors present in mobile commerce. Data were collected in an online survey and analyzed via structural equations modeling. Results suggest that trust transferred from online contexts and ease of use have significant effects on mobile trust formation, while also indicating that mobile trust influences consumers' attitudes and intentions to purchase using mobile devices.
\end{abstract}

Key words: trust; mobile commerce; attitude; intention to purchase; trust transference. 


\section{Introduction}

It's probable that the Internet is the most important innovation of the last fifty years, as it allows interactions and transactions to take place without time and space limitations. Online shopping, along with other computer-mediated transactions characterized by faceless and intangible factors, is greatly affected by fear and anxiety. In such a context, lack of trust can be considered the utmost barrier preventing online transactions from taking place (Beldad, de Jong, \& Steehouder, 2010). Knowing what is the nature of trust, particularly in online environments, and what are its determinants becomes essential to the building of competitive advantage and the acquisition and retention of consumers.

More recently, developments in technology have enabled entities to establish pervasive electronic presence anytime, anywhere via mobile devices. As the quantity of such devices multiplies, a huge number of adopters subscribe to service providers, and thus become a growing market for mobile transactions, communications and promotion (Shankar, Venkatesh, Hofacker, \& Naik, 2010; Varnali \& Toker, 2010). Mobile devices present themselves as very personal devices, which may provide firms with unrivaled possibilities to build and maintain one-to-one relationships with their customers. A set of unique features such as ubiquity, constant reach ability, personalization, and localization (Camponovo, Pigneur, Rangone, \& Renga, 2005) allows the identification of each user and their geographical position by tracking the specific ID of a mobile device. These developments in the consumer environment have made mobile-marketing research an attractive perspective. Despite the unique benefits of mobile services, overcoming trust issues is also a major obstacle for their adoption, with many customers feeling as uncomfortable, or perhaps more so, with sharing personal information and conducting transactions over wireless portable devices as they feel about doing so over wired desktops.

If trust is more difficult to build in the mobile environment because of mobile commerce's greater uncertainties and risks (Siau, Sheng, Nah, \& Davis, 2004), a possible way to solve trustbuilding issues would be transferring trust from existing channels to $\mathrm{m}$-commerce. According to Stewart (2003), consumer trust can be transferred from one context to another and that could turn previously extant channels into powerful tools for building trust. On the other hand, if trust transference alone was sufficient for success, brick and click retailers should excel in their mobile retail and outperform purely online retailers; this, however is not always the case (Kuan \& Bock, 2007). Empirical studies indicate that several factors are determinants of trust and perceptions of trustworthiness in online and mobile exchanges (Bart, Shankar, Sultan, \& Urban, 2005; Beldad et al., 2010). Therefore, there must be other factors that impact customer trust, with some of them possibly being exclusive to mobile contexts.

Despite the importance of trust for mobile commerce, there has been little academic effort made to study the relationships between mobile devices unique components of interactivity and customer trust, or the relationship between previous extant offline trust and online trust, and mobile trust formation. Furthermore, no trust-mediated model explaining intention to buy via mobile devices found in extant literature takes into consideration, at the same time, mobile technologies' particular characteristics, consumers' affections and consumers' past experiences in different channels. This research aims to fill that gap.

This study proposes a framework that incorporates trust transference and mobile services' unique characteristics to more general factors in an attempt to identify relevant trust determinants, presenting a trust-mediated model for consumer attitude and transaction intentions in mobile commerce contexts. In order to construct a relevant framework, this research builds its basis on: the (a) Theory of Reasoned Action (Fishbein \& Ajzen, 1975), the (b) Categorization theory (Cohen \& Basu, 1987), and the (c) Innovation Diffusion Theory (Rogers, 1983), as well as on the Technology Acceptance Model (Davis, 1989; Venkatesh \& Davis, 2000), and the Web Trust Model (McKnight, Choudhury, \& Kacmar, 2002). By adding mobile specific factors and trust transference to existing 
theories and models, this study intends to improve the understanding of mobile trust formation and open new venues for researching mobile trust and addressing mobile transactions trust issues.

\section{Theoretical Background and Hypotheses}

\section{Trust}

Trust is a concept that is under constant discussion and different definitions have emerged from each of the disciplines which have examined it (Beldad et al., 2010; Urban, Amyx, \& Lorenzon, 2009). Generally speaking, trust definitions can be divided in two major streams. One stream treats trust as an expectation regarding the behavior of an interaction partner (Garbarino \& Johnson, 1999; Morgan \& Hunt, 1994), whereas the other considers it to be a psychological state comprising acceptance of and exposure to vulnerability (Mayer, Davis, \& Schoorman, 1995; Rousseau, Sitkin, Burt, \& Camerer, 1998). In addition, trust definitions have evolved to a point were some consistency can be reached by focusing on three of its dimensions: integrity/credibility, ability/competence and benevolence (Urban et al., 2009). Whereas credibility, integrity, ability and competence dimensions are connected to the provider's transactional behavior and its structural and technological capacities, benevolence is directly connected to consumers' beliefs about a provider's good will and intentions (Hwang \& Kim, 2007).

\section{Online trust}

Using offline expectation-based definitions of trust as a starting point, researchers have elaborated upon one another's definitions and emphasized the specific characteristics of online environments to form online trust definitions. Connotations of credibility, integrity, reliability, confidence and benevolence, and characteristics of offline trust were preserved in its online counterpart, but new connotations were added, such as the inclusion of consumer perceptions of a website's credibility (Bart et al., 2005).

Nevertheless, there are also important differences between online and offline trust regarding its objects. Whereas offline trust is directed only at people or organizations, online trust involves technology (hardware, software and the internet) and the entity deploying it (Boyd, 2003). In short, online trust is built when individuals or organizations form positive impressions of an online interaction means and are willing to accept vulnerability in dealing with it. Another difference is that, in online transactions, research indicates that trust appears to directly affect purchase intention and behavior (Shankar, Urban, \& Sultan, 2002), whereas in offline transactions trust mediates the decision process but not actual purchase behavior (Doney, Cannon, \& Mullen, 1998).

\section{Mobile trust}

Mobile contexts are similar to online contexts, but they are not the same. Similarly to online transactions, mobile transactions involve not only people and organizations, but also the technologies applied by them during their interactions with consumers. However, mobile services rely on cellular telecommunication networks and mobile devices, having some features that are not present in similar online services. Characteristics such as mobility, ubiquity, and contextual offers are exclusive to mobile contexts (Shankar \& Balasubramanian, 2009; T. Lee, 2005). On the other hand, limitations due to the specifics of cellular networks and mobile devices, such as slower speed, simpler functions, small screens and network instability combine to build greater uncertainties and risks that prevent consumers from using mobile services and commerce (Siau et al., 2004; T. Lee, 2005).

Using T. Lee's (2005) definition as a starting point this study defines mobile trust as one's willingness to accept vulnerability while interacting with another through a mobile device given extant expectations regarding intentions and behavior of the other party. 


\section{Trust, attitudes, intentions and behavior}

Fishbein and Ajzen's (1975) theory of reasoned action (TRA) provides background for understanding the relationship between attitudes, intentions and behaviors based on the premise that human beings make decisions based on the information available. According to the theory the best determinant of an individual's behavior is intent, which is the representation of one's readiness to perform a certain behavior. Intention is preceded by subjective norms (social influences and motivations) and attitude (personal beliefs). McKnight, Choudhury and Kacmar (2002) applied a more parsimonious version of the TRA and proposed a Web Trust Model (WTM) that postulates that trust beliefs lead to trusting intentions, which in turn influence trust-related behaviors, including personal information disclosure and monetary transactions. Furthermore, Dimitriadis and Kyrezis (2010) affirm that trust intentions influence trust-related behaviors, indicating intention to use a technology as one such behavior.

Supported by TRA and the WTM, and assuming that a purchase is a trust-dependent behavior (Beldad et al., 2010; Hoffman, Novak, \& Peralta, 1999), this study proposes that trust works as a mediator between consumers' cognitive evaluations and their attitudes and purchase intentions regarding mobile commerce transactions. The effects of each antecedent on trust (the effects that will be mediated by trust in relation to attitude and intention) are discussed in the following sections. Thus, we can hypothesize that trust exerts a direct effect on a consumer's attitude and intention towards the use of mobile commerce services.

Hypothesis 1: Trust in mobile commerce has a direct positive effect on a consumer's attitude towards using mobile devices to make a purchase.

Hypothesis 2: Trust in mobile commerce has a direct positive effect on a consumer's intention to use a mobile device to make a purchase.

Hypothesis 3: A consumer's attitude towards using mobile devices to make a purchase has a direct positive effect on his/her intention to use a mobile device to make a purchase.

\section{Trust determinants}

Empirical studies have indicated that several factors are determinants of trust and perceptions of trustworthiness in online exchanges. Propensity to trust, experience and proficiency in technology usage, perceived ease of use, information quality, graphical characteristics, customization and personalization, privacy and security, third-party guarantees, reputation and offline presence are all relevant determinants for trust (Beldad et al., 2010; D. J. Kim, Ferrin, \& Rao, 2008; Lin, Lu, Wang, \& Wei, 2011; Urban et al., 2009).

Regarding mobile services, studies have examined determinants and consequences of trust and found that: (a) trust can be predicted by perceived ease of use and disposition to trust (J. Zhang \& Mao, 2008), (b) trust increases behavioral intention to accept advertising (J. Zhang \& Mao, 2008), and that (c) perceived components of interactivity, such as responsiveness, connectedness, ubiquity and contextual offer have strong and significant effects on customer trust (T. Lee, 2005).

\section{Trust transference}

According to Lin, Lu, Wang and Wei (2011) trust transfer is a cognitive process that may arise from one familiar context to a new context or from one trusted entity to an unknown entity. Categorization theory suggests that consumer knowledge of products or brands is stored in memory as structures (Cohen \& Basu, 1987). These memory structures regard similarly perceived objects as belonging to a common category and associated object-based knowledge. Therefore, if a new instance appears to belong to a previously defined category, the evaluations and perceptions associated with that category can be transferred to the new occurrence. Based on categorization theory mobile services 
can then be viewed as being similar to other online or offline services. In short, if consumers trust a certain service or provider, this trust could be transferred to its mobile version.

Marketing and e-commerce research indicate that trust transference can occur both intra-channel, when trust is transferred from an entity to another in the same channel (Ballester \& Espallardo, 2008; Stewart, 2003, 2006), and inter-channel, when trust is transferred from one context to another, mainly offline to online (Hahn \& Kim, 2009; Kuan \& Bock, 2007) or from online to mobile (Lin et al., 2011).

Multiple studies point out that offline presence enhances online trust but, first and foremost, it is word-of-mouth which exerts dominant effect in such cases, not offline trust (Kuan \& Bock, 2007). So, while offline trust is transferred to online contexts it does not play a major role in online trust formation. However, Lin et al. (2011) found that trust in online brokerage services is significantly related to the initial trust in mobile brokerage services. It is clear that online trust can be transferred to mobile environments and seems to be an important determinant of trust in mobile contexts. Based on the categorization theory and previous empirical evidence regarding trust transfer, this study proposes that trust built in offline and online channels is transferred to the mobile channel.

Hypothesis 4: Trust in online commerce has a direct positive effect on trust in mobile commerce.

Hypothesis 5: Trust in offline commerce has a direct positive effect on trust in mobile commerce.

\section{Ease of use and usefulness}

The technology acceptance model (TAM) states that there are two especially important determinants influencing a system's usage: Perceived usefulness and perceived ease-of-use (Davis, 1989). Davis (1989) defines the first, perceived usefulness, as the degree a person believes that using a particular system would enhance his or her performance; and the second, perceived ease-of-use, as the degree to which a person believes that using a particular system would be free of effort.

Diffusion of innovation theory also suggests prominent roles for both usefulness and ease-ofuse. According to Rogers (2003), characteristics of innovations help to explain their different rates of adoption. Among these characteristics of innovations are relative advantage, defined as the degree to which an innovation is perceived as better than the idea it supersedes, and complexity, defined as the degree to which an innovation is perceived as difficult to understand and use (Rogers, 2003). There is a clear parallel between perceived usefulness and relative advantage, and between perceived ease-ofuse and complexity. If relative advantage represents a combination of beliefs about a new idea that would make it be perceived as superior to another, then being able to improve one's performance when used is, without a doubt, a characteristic that would make an idea be perceived as superior to others. Now, the parallel between complexity and ease of use is even clearer since both work with beliefs of how difficult to use something is in relation to what is already in use.

Mobile services are obviously both innovations and technology systems. Therefore, perceived ease-of-use and perceived usefulness should play important roles as trust determinants in technology mediated interactions, acting as buffers to perceived risks and boosters to confidence. This study proposes that both perceived usefulness and perceived ease-of-use are determinants of trust in mobile commerce contexts.

Hypothesis 6: Perceived usefulness has a direct positive effect on trust in mobile commerce.

Hypothesis 7: Perceived ease-of-use has a direct positive effect on trust in mobile commerce.

What's more, in face of technological and interactive constraints, such as small keyboards, small screens, limited time spans, and multitasking, the use of mobile devices can be both mentally and physically strenuous (Gao, Rohm, Sultan, \& Huang, 2012; J. Zhang \& Mao, 2008). Therefore, the 
perception that a mobile transaction is easy and uncomplicated would increase perceptions of benefits regarding mobile commerce and improve attitude towards it (Davis, 1989; Gao et al., 2012). Based on this, our study proposes that perceived ease-of-use will also be a predictor of perceived usefulness.

Hypothesis 8: Perceived ease-of-use has a direct positive effect on perceived usefulness.

\section{Mobility and contextual offer}

Due to the mobile characteristics of wireless devices and networks, mobile commerce services operate in a very different context from e-commerce (Siau, Lim, \& Shen, 2001). Again, diffusion of innovation theory (Rogers, 2003) suggests that an innovation's characteristics help to explain its adoption and use. Two advantages of mobile commerce in relation to e-commerce would be mobility and contextual offer.

Mobility, the possibility to access services and make transactions in real time, even while commuting or traveling, is a significant differentiating characteristic of mobile services (Siau \& Chen, 2003) and it can reduce consumer perceptions of social and psychological risks, thus enhancing trust (M. S. Y. Lee, McGoldrick, Keeling, \& Doherty, 2003).

Another significant advantage of mobile commerce is contextual offering. At first, context has three aspects: a personal context, a time context and an environmental context (H. Kim, Kim, Lee, Chae, \& Choi, 2002). Next, Figge (2004) adds the concept of situation dependency which represents the spatial, personal and temporal contexts associated with mobile services access. In sum, the concept of contextual offers applies to specific mobile features that enable the delivery of customized, relationship-based, timely, and location specific packets of information or offerings to users (T. Lee, 2005). Being provided with contextually relevant information directed to one's profile seems to be an optimal way to improve consumer confidence in an organization or service, thus positively influencing their trust.

Both mobility and contextual offers are present in mobile commerce and represent characteristics that could be considered relative advantages of mobile commerce when compared to extant ways to perform commercial transactions according to diffusion of innovation theory. This study proposes that these two mobile specific characteristics are important determinants of trust in mobile commerce.

Hypothesis 9: Perceived mobility has a direct positive effect on trust in mobile commerce.

Hypothesis 10: Perceived contextual offers have a direct positive effect on trust in mobile commerce.

\section{Enjoyment}

As the Internet is often used not only for work but also for entertainment and pleasure, it can be argued that entertaining features should play an important role in its adoption and use. Different studies have consistently demonstrated that employing dimensions of entertainment to TAM seems to add a significant predictor to the intention to use as well as attitude towards the adoption of a technology (J. Zhang \& Mao, 2008). Enjoyment refers to an individual's subjective experience of a human-computer interaction, defined as the extent to which an individual believes that the activity of using a product or service is perceived as enjoyable in its own right, apart from any performance consequences that may be anticipated (L. Zhang, Zhu, \& Liu, 2012). Hence, perceived enjoyment is argued to be a direct determinant of attitude and intentions toward technologies (L. Zhang et al., 2012; Nysveen, Pedersen, \& Thorbjornsen, 2005). According to Hwang and Kim (2007), affect infusion, a process where affective loaded information influences and is incorporated into judgmental processes, would allow affective reaction variables such as enjoyment to influence multi-dimensional e-trust (online trust) constructs. Thus, this study proposes that mobile commerce has a dimension of 
entertainment and pleasure, regarding both the use of the Internet and the shopping experience, and that this dimension affects mobile trust building just as it affects online trust.

Hypothesis 11: Perceived enjoyment has a direct positive effect on trust in mobile commerce.

Figure 1 shows the model proposed by this study combining trust determinants, trust, trust transference between channels and intention to purchase via mobile devices.

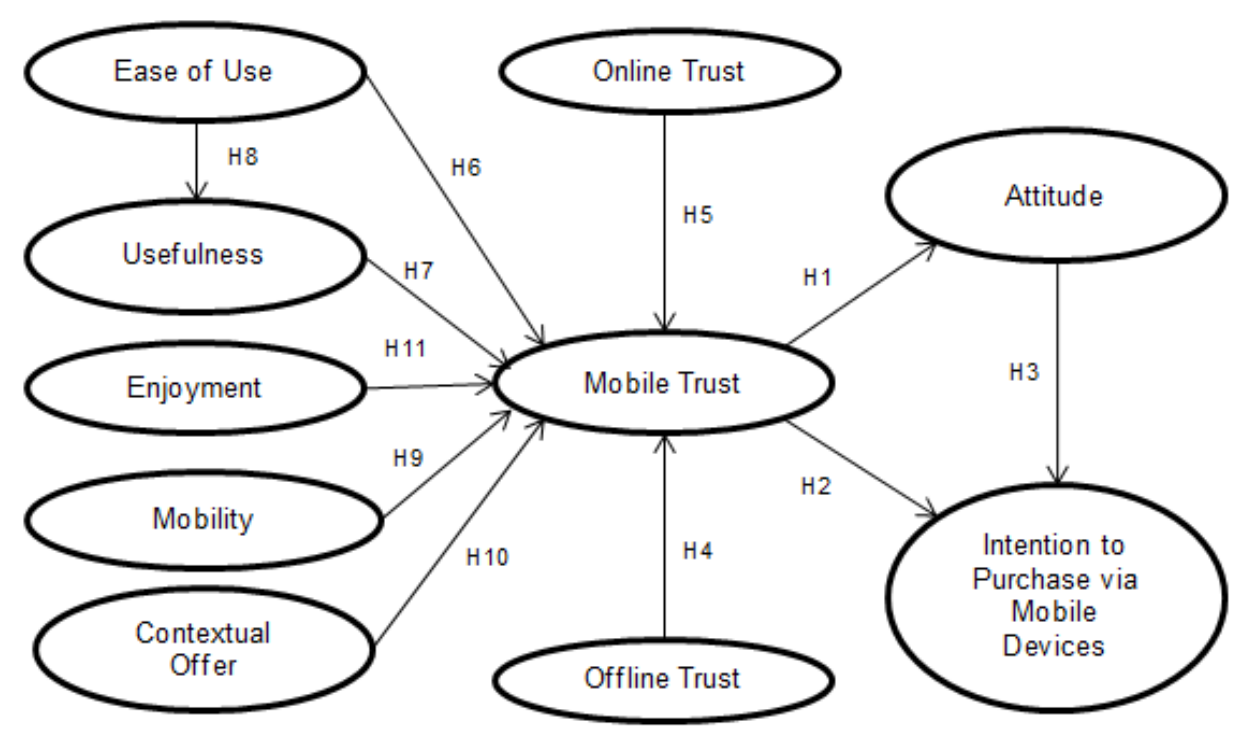

Figure 1. Proposed Research Model

\section{Method}

In order to test the proposed hypotheses, this study made use of a cross-sectional survey with a non-probabilistic sample of the population of interest. The majority of studies on consumer behavior and trust have used this same method (D. J. Kim et al., 2008; Kuan \& Bock, 2007; L. Zhang et al., 2012; Lin et al., 2011; Zhou, 2011).

Although the goal of this study is not to evaluate a particular innovation, we consider it important to limit what devices can be used to provide mobile commerce services in order to better evaluate responses. Thus, only smartphones, tablets and cellular phones with internet connection were considered mobile devices.

\section{Operationalization of variables}

This study used the following scales already developed and tested in extant literature for the measuring all constructs involved in the model to ensure their reliability and validity: three scales (Kuan \& Bock, 2007), each one with three items, to measure each of the three different kinds of trust evaluated (Mobile, Online and Brick-and-Mortar Trust); a three-item scale to measure Perceived Usefulness (C. Kim, Mirusmonov, \& Lee, 2010); a four-item scale for Perceived Ease of Use (Nysveen et al., 2005); a three-item scale for Perceived Mobility (C. Kim et al., 2010); a three-item scale to measure Perceived Contextual Offer (T. Lee, 2005); a four-item scale to measure Perceived Enjoyment (Nysveen et al., 2005); a three-item scale to assess Attitude towards using mobile devices to make a purchase (T. Lee, 2005); and a three-item scale to assess Intention to use a mobile device to 
make a purchase (Khalifa \& Shen, 2008). Even though trust has many available scales, some with quite a few items per dimension, the choice for a three-item scale with each item being associated with one of the dimensions of trust (benevolence, integrity/credibility and ability/competence) is justified by current literature employing trust as a single construct. Besides Kuan and Block's (2007), from which the trust scales for each purchasing environment are drawn, other papers in relevant journals have used similarly-sized scales (consisting of three or four items) to measure trust as a single construct (Bart et al., 2005; Garbarino \& Johnson, 1999; Gefen, 2000; D. J. Kim, Ferrin, \& Rao, 2009; T. Lee, 2005; Lin et al., 2011). The goal of this paper was not to evaluate the three different dimensions of trust as separate constructs.

The questionnaire was translated into Portuguese and then back-translated into English to ensure items were worded as close as possible to their original versions in English. A first pretest was made with a small sample of marketing professors, graduate students and professionals to evaluate if the Portuguese version was adequate and precise, leading to minor alterations in item wording. A second pretest of the complete questionnaire was administered to a sample of 15 graduate students to provide feedback regarding questionnaire structure and question clarity. A final pretest of the online version of the questionnaire was distributed to a sample of 8 undergraduate students to check final presentation, overall comprehensiveness and online functions. After pretesting, the final research instrument consisted of a total of 32 items measured by five-point Likert scales, three control items and six items related to demographic variables. All scale items utilized in the research instrument are illustrated in the Appendix.

\section{Sample and Data Collection Procedures}

The study population comprised Brazilian undergraduate students living in Rio de Janeiro and their personal connections contacted via social networks (Facebook and LinkedIn). A snowball sampling (Goodman, 1961) technique was used to distribute the questionnaire, with undergraduate students from two different private universities receiving e-mails containing links to the research instrument and instructions to redistribute it to other students in their social networks. This kind of non-probabilistic sampling is known to improve sample homogeneity, usually excluding extreme outliers that are not immediately available (Hair, Black, Babin, \& Anderson, 2010). All questionnaires were administered via the same online survey website.

Kulviwat, Bruner, Kumar, Nasco and Clark (2007) highlight the fact that a young, tech elite should be an interesting market segment for the introduction of new technologies because their adoption and use influences what other more conservative groups eventually do, emphasizing that members of this elite group average twenty-two years of age and spend more than average on technology-related products and services. Undergraduate students fit well this definition, representing a meaningful group for studies on consumer behavior related to new technologies (S. Lee, Ha, \& Widdows, 2011). An age limit of 30 years was set for the respondents, in order to provide homogeneity to the sample (avoiding unwanted moderating effects) and to keep its emphasis on the young tech elite as defined by Kuliwat et al. (2007).

An initial sample of 427 respondents was obtained. 179 questionnaires were eliminated because of missing data (56), age over 30 (119) or not having access to a mobile device (4), resulting in a final sample comprised of 248 valid questionnaires. Missing data issues were all related to incompletion of the questionnaire due to interruption (questionnaire was blank after a certain point), with no variable reaching a missing data percentage above the $15 \%$ literature limit recommendation (Hair et al., 2010). Nonetheless, in order to avoid issues related to dependent variables containing missing data, authors decided to delete all 56 cases with missing data. The average age of the survey participants was 21.9 years old, with a standard deviation of 3.51. The majority of the sample was female (52.8\%), single (86.3\%), and 66.5\% belonged to upper class (household income above R \$10,000 per month). 


\section{Results}

\section{Test for common method variance}

Since both dependent and independent variables in this study were opinions collected from the same respondents, common method variance could pose a problem. As suggested by Podsakoff and Organ (1986), this study employed Harman's one-factor test to examine how present such bias was in survey data. The results of principal component analysis indicated the presence of twelve factors with an eigenvalue greater than 1 , whilst none of the factors accounted for almost all variance (the factor that explained the most captured only $30 \%$ of the total variance). In addition, the analysis of correlations between item residuals showed there was no particularly significant correlation between item residuals. Given such an outcome, common method variance seems not to be an issue in this case (Podsakoff \& Organ, 1986).

\section{Measurement model}

The first step in analysis of the data was a confirmatory factor analysis (CFA) to test the validity, unidimensionality and reliability of the scales used in the measurement model. The final measurement model, with 32 indicators, showed good fit indexes (RMSEA $=0.060$ with C.I. of 0.056 to 0.064 , $\mathrm{SRMR}=0.056, \mathrm{CFI}=0.918, \mathrm{IFI}=0.919, \mathrm{TLI}=0.909, \mathrm{GFI}=0.892, \mathrm{NFI}=0.912, \chi^{2} / \mathrm{df}=2.32, \chi^{2}=$ 1613.75, $\mathrm{df}=695)$.

Face validity of the employed scales was achieved by reliance on scales already used in the literature and by having marketing researchers carefully examine the item wording of the translated scales before their employment.

Concerning nomological validity, the correlation matrix between constructs shows that those relate positively with each other (Table 1, correlations are above the main diagonal). Given that all correlations are positive and consistent with the related theory (Hair et al., 2010), it can be said that the constructs exhibit nomological validity.

Average variance extracted (AVE) for each construct was calculated in order to test convergent validity. Calculated AVE values were between 0.66 and 0.83 , estimates greater than 0.50 , indicating convergent validity as suggested by Fornell and Larcker (1981). Moreover, scales used met the minimum standards of reliability, with all scales presenting values between 0.76 and 0.95 for the alpha coefficient and between 0.80 and 0.95 for composite reliability (Nunnally \& Bernstein, 1994).

To verify discriminant validity, Fornell and Larcker (1981) suggest comparing the average variance extracted (AVE) with the shared variance (the squared correlation coefficient) between all pairs of constructs. As the results on Table 1 indicate (diagonal has the AVE values for each construct and below the diagonal are the squared correlations), all shared variances were lower than the AVE by the items measuring the constructs, thus indicating adequate discriminant validity. 
Table 1

Correlation and Discriminant Validity Matrix

\begin{tabular}{lcccccccccc}
\hline Construct Name & $\mathbf{1}$ & $\mathbf{2}$ & $\mathbf{3}$ & $\mathbf{4}$ & $\mathbf{5}$ & $\mathbf{6}$ & $\mathbf{7}$ & $\mathbf{8}$ & $\mathbf{9}$ & $\mathbf{1 0}$ \\
\hline 1. Ease of Use & $\mathbf{0 . 6 6}$ & 0.64 & 0.45 & 0.51 & 0.32 & 0.14 & 0.16 & 0.51 & 0.57 & 0.47 \\
2. Usefulness & 0.41 & $\mathbf{0 . 6 9}$ & 0.50 & 0.60 & 0.42 & 0.22 & 0.15 & 0.37 & 0.74 & 0.61 \\
3. Enjoyment & 0.20 & 0.25 & $\mathbf{0 . 8 3}$ & 0.46 & 0.43 & 0.15 & 0.11 & 0.25 & 0.68 & 0.53 \\
4. Mobility & 0.26 & 0.36 & 0.21 & $\mathbf{0 . 6 0}$ & 0.43 & 0.14 & 0.08 & 0.24 & 0.53 & 0.45 \\
5. Context. Offer & 0.11 & 0.18 & 0.19 & 0.19 & $\mathbf{0 . 7 0}$ & 0.19 & 0.16 & 0.25 & 0.51 & 0.46 \\
6. Offline Trust & 0.02 & 0.05 & 0.03 & 0.02 & 0.04 & $\mathbf{0 . 6 0}$ & 0.24 & 0.20 & 0.20 & 0.13 \\
7. Online Trust & 0.03 & 0.02 & 0.01 & 0.01 & 0.03 & 0.06 & $\mathbf{0 . 6 0}$ & 0.48 & 0.22 & 0.23 \\
8. Mobile Trust & 0.26 & 0.13 & 0.06 & 0.06 & 0.06 & 0.04 & 0.23 & $\mathbf{0 . 6 6}$ & 0.44 & 0.47 \\
9. Attitude & 0.32 & 0.56 & 0.47 & 0.28 & 0.26 & 0.04 & 0.05 & 0.19 & $\mathbf{0 . 7 0}$ & 0.83 \\
10. Intention & 0.23 & 0.38 & 0.28 & 0.20 & 0.21 & 0.02 & 0.05 & 0.22 & 0.69 & $\mathbf{0 . 7 5}$ \\
\hline
\end{tabular}

Note. Correlations are above the main diagonal, Squared Correlations are below. Main diagonal contains AVE values. All correlations were significant at a level of 0.05 or below.

\section{Structural model}

To test the proposed model and the research hypotheses, the study employed structural equation modeling (SEM). In SEM, the significance of the estimated coefficients for the hypothesized relationships in the model indicates whether the relationship between constructs appears to hold true or not (Byrne, 2010). All indices indicated good fit of the model to the data. The ratio $\chi^{2} / \mathrm{df}$ was 2.70 ( $\chi^{2}$ $=1308.45 \mathrm{df}=484)$, lower than the value of 3.0 suggested by Byrne (2010). Moreover, the incremental fit indexes were greater than 0.90, with a CFI of 0.91, a TLI of 0.90, a NFI of 0.90 and an IFI of 0.91. In turn, the absolute fit indexes were also acceptable according to the literature (Byrne, 2010; Hair et al., 2010; Hu \& Bentler, 1999), indicating a good fit of the model: RMSEA $=0.073$ (C.I. 0.068 to 0.078$),$ SRMR $=0.076$ and $\mathrm{GFI}=0.88$.

Verification of each of the research hypotheses was performed with an analysis of magnitude, sign and significance of the standardized path coefficients (Byrne, 2010). The estimated path coefficients, together with the research hypotheses and associated significance levels, appear in Table 2. The structural model was able to explain $39 \%$ of the variability of mobile trust, $22 \%$ of the variance of attitude and $45 \%$ of the variability of intention to buy via mobile devices.

Table 2

Estimated Path Coefficients, Significance and Hypotheses Testing

\begin{tabular}{lccc}
\hline Path & $\begin{array}{c}\text { Standardized } \\
\text { Coefficient }\end{array}$ & p-value & $\begin{array}{c}\text { Hypothesis } \\
\text { Support }\end{array}$ \\
\cline { 1 - 1 } H1: Mobile Trust $\rightarrow$ Attitude & 0.47 & $<0.001$ & YES \\
\cline { 1 - 1 } H2: Mobile Trust $\rightarrow$ Intention & 0.20 & $<0.001$ & YES \\
\cline { 1 - 1 } H3: Attitude $\rightarrow$ Intention & 0.76 & $<0.001$ & YES \\
\cline { 1 - 1 } H4: Offline Trust $\rightarrow$ Mobile Trust & -0.01 & 0.971 & NO \\
\hline
\end{tabular}


Table 2 (continued)

\begin{tabular}{lccc}
\hline Path & $\begin{array}{c}\text { Standardized } \\
\text { Coefficient }\end{array}$ & p-value & $\begin{array}{c}\text { Hypothesis } \\
\text { Support }\end{array}$ \\
\cline { 1 - 1 } H5: Online Trust $\rightarrow$ Mobile Trust & 0.41 & $<0.001$ & YES \\
\cline { 1 - 1 } H6: Ease of Use $\rightarrow$ Mobile Trust & 0.37 & $<0.001$ & YES \\
\cline { 1 - 1 } H7: Usefulness $\rightarrow$ Mobile Trust & 0.14 & 0.088 & NO \\
\cline { 1 - 1 } H8: Ease of Use $\rightarrow$ Usefulness & 0.62 & $<0.001$ & YES \\
\cline { 1 - 1 } H9: Mobility $\rightarrow$ Mobile Trust & -0.03 & 0.639 & NO \\
\cline { 1 - 1 } H10: Contextual Offer $\rightarrow$ Mobile Trust & 0.09 & 0.128 & NO \\
\cline { 1 - 1 } H11: Enjoyment $\rightarrow$ Mobile Trust & 0.02 & 0.718 & NO \\
\hline
\end{tabular}

\section{Discussion}

\section{Trust, attitude and intention to purchase}

The results establish trust as an important antecedent to young consumers' attitudes towards purchasing via mobile devices, indicating that trust plays an important part in how consumers build their views about mobile commercial transactions and, in a lesser degree, how ready they are to purchase via mobile devices. The effects exposed here are consistent with those observed by other researchers (Dimitriadis \& Kyrezis, 2010; D. J. Kim et al., 2008; Kuan \& Bock, 2007; Lu, Yang, Chau, $\&$ Cao, 2011; T. Lee, 2005; Zhou, 2011) for trust effects on attitude and intention separately.

\section{Trust transference}

As also seen by Lin et al. (2011) and Lu, Yang, Chau and Cao (2011), online trust presented a direct positive effect on mobile trust. The results seem to indicate that offline trust plays no relevant part as a mobile trust antecedent whereas online trust plays an important part. Previous studies show that offline trust has little effect over online trust and that other factors have greater influence (Kuan \& Bock, 2007). Thus, it's possible that offline trust also has no observable effect on mobile trust. A few possible explanations for this occurrence could be (a) the absence of strong offline brands among mobile commerce sites and applications, (b) the impossibility for consumers to perceive their shopping experience offline and via mobile devices as belonging to the same category, thus making previous knowledge and evaluations not transferable according to categorization theory (Cohen \& Basu, 1987), and (c) the reasonable likelihood that most mobile commerce services only share similarity with online ones, making categorization processes between mobile and offline commerce impossible.

\section{Ease of use and usefulness}

The direct positive effect of ease of use on mobile trust and the insignificant effect of usefulness on trust found are not consistent with any results observed in previous studies on mobile commerce. Actually, even though the effect of usefulness on mobile trust could be considered significant (albeit very small, with a 0.14 magnitude) at a level of significance of $10 \%$ (p-value was 0,088 ), both these results are the exact opposite of the findings by Dimitriadis and Kyrezis (2010) for banking operations via telephones in contrast with online operations. It is possible that mobile devices may now be so familiar to consumers that they are perceived as useful no matter their application, but perhaps their specific use as a commercial transaction platform is still surrounded by uncertainty, thus making ease of use, but not usefulness, a relevant antecedent to trust. The direct positive effect of ease of use on 
usefulness is consistent with effects seen by other studies (C. Kim et al., 2010; Gao et al., 2012) and reinforces notions that fast and simple operations increase consumers' perception of a technology's usefulness.

\section{Mobility and contextual offer}

Both mobility and contextual offer presented insignificant effects on trust. This result contradicts previous studies regarding the effects of mobility and contextual offer on consumers' trust (Lin et al., 2011; T. Lee, 2005; T. Lee \& Jun, 2007), but it's possible that Brazilian consumers perceive mobility and contextual offer as irrelevant in relation to purchases via mobile devices because of specific characteristics of Brazilian mobile services and Brazilian mobile offers. T. Lee (2005) considers mobility a relevant factor in trust building when it facilitates communications between provider and consumer. Given that, mobile network quality and speed might affect the relevance of mobility. Brazilian consumers might not yet consciously recognize the advantages of being able to purchase something at any time or place because of the country's notoriously unreliable mobile networks infrastructure and services. Regarding contextual offer, T. Lee and Jun (2007) and T. Lee (2005) affirm that a contextual offer is dependent of its perceived value, which requires the offer to be aligned with a real need for a service, information or product. So, unless consumers can see some relevance on the content of offers received, those offers become meaningless or, even worse, are perceived as a privacy invasion. Since the vast majority of mobile offers in Brazil seem to be related only to the advertising of mobile carriers' products, billing or swindling schemes instead of serious attempts to attend consumer needs while being mindful of their contexts, it seems that Brazilian consumers consider contextual offers irrelevant at the time of the study.

\section{Enjoyment}

No significant effect of enjoyment on trust was found. At first, this finding seems to contradict previous studies (Hwang \& Kim, 2007), but Chung and Tan (2004) affirm that, in order to enjoy something, consumers evaluate its content, response and ease of use. Furthermore, Wang and Wang (2010) reinforce that concept and add to it by suggesting that mobile devices' lack of feedback and speed may interfere in users' perceived enjoyment negatively. Moreover, the reliability of the mobile networks may render enjoyment perception null. On the other hand, according to Hwang and Kim (2007), it seems that enjoyment does not affect the benevolence dimension of trust, only impacting upon trust dimensions related to the provider's transactional behavior. This study, given its general approach towards mobile commerce sites and applications, in which no brands or specified sites or applications are used as reference, may have placed more focus on the benevolence side of trust, reducing the importance of the institutional and transactional dimensions of the construct, which might otherwise have been impacted by perceived enjoyment.

\section{Conclusions and Implications}

\section{Theoretical implications}

The study points to direct effects of cognitive constructs on consumer trust, particularly of those related with the use of the technology.

As expected, according to Categorization Theory, online transactions share enough characteristics with mobile ones to allow knowledge and perceptions regarding online purchases to be associated with mobile commerce, thus allowing trust built in online interactions to be transferred to mobile ones. On the other hand, offline transactions seem to be placed in a completely different category and are not relevant in building mobile commerce trust. This new finding could be the result of a lack of commonalities regarding the transactions themselves or caused by the still incipient 
number of organizations operating in both offline and mobile commerce. This particular result seems to implicate that bad online experiences may negatively affect consumer beliefs in the technologies and organizations involved in their mobile transactions and interactions, and thus their trusting intentions, while their offline experiences play little to no part in building their expectations regarding mobile transactions.

As suggested by Ajzen's Theory of Reasoned Action, consumers' beliefs, particularly in technologies and organizations involved in mobile transactions and interactions, may interfere in their purchase behavior regarding the use of mobile devices to acquire both products and services. Mobile trust seems to influence both consumer attitude towards and intention to buy via mobile devices in general terms. This finding underscores the importance of trust in forming consumer attitudes and intentions regarding mobile purchases and implies that perceptions of credibility and reliability of the organizations involved in the transaction and the technologies employed by them are paramount in influencing consumer behavior. The findings also confirm the mediating effect of trust in trust-related attitudes and intentions.

Finally, while appointed by literature as relative advantages of mobile technology (Rogers, 2003), which would boost mobile commerce adoption and use over previously existing channels (offline and online), certain mobile technologies and their features appear to be dependent on content and responsiveness to be considered relevant by consumers. In that regard our results imply that, for the young Brazilian consumer, mobility and contextual offer are not a particular determinant of their mobile trusts. Similarly, consumer judgments involved in building trust in mobile commerce seem to lack the influence of enjoyment, indicating a more practical approach to mobile transactions.

It's important to highlight that this study evaluates trust transference effects on mobile trust and mobile trust effects on attitude and intention without the use of reference organizations, institutions or brands, thus removing biases related to their influence. This study is also the first to construct and test a model in which trust is proposed to fully mediate the effects of characteristics unique to mobile services, affective reactions to use, technology usability and perception transference from other channels on consumer attitude and intention to buy via mobile devices.

\section{Practical implications}

Providers should keep in mind that simple and responsible interfaces are important in mobile commerce transactions. Consumers shouldn't waste their time trying to find the right products or making a purchase. Familiar and simple technologies are more valuable in building customer trust than those involving complex interactions. Thus, using processes similar to those employed online during product search and payment via mobile devices, instead of introducing new processes which would require learning, may represent a relevant competitive advantage.

Furthermore, since trust has a considerable influence on consumers' attitude and intentions related to mobile commerce, thus influencing their actual purchase behavior, it becomes essential to provide clear indication of credibility and reliability to both the organization and the technologies it employs to deliver its services. A good business practice might be to promote trust via the presentation of clear return and privacy policies or employing visual displays of security and quality certifications. Connections to other organizations considered to be trustworthy could also be an advantage.

Lastly, it appears that certain mobile technologies features, such as contextual offer, are dependent of content presented and responsiveness to be considered relevant by consumers. Thus, the indiscriminate or incorrect use of these features may lead to loss of perceived credibility and relevance, if not to consumer resentment. Organizations should avoid sending messages and offers which are too generic in content and focus on those which content is pertinent to individual or small groups needs in order to remain relevant in the consumers' minds. 


\section{Limitations and Future Research}

An important limitation of the study relates to the collection and processing of data. Regarding the external validity of the results, given the convenience sample taken, it is quite possible that the relationships found in this study do not apply exactly as presented to other types of consumers. In addition, this study is based on conceptual questions, not on reference services, service providers or brands; thus it's possible that some findings are a result of consumers' inability to connect abstract concepts to real life experiences. This might have led to the unexpected results found here for mobility, contextual offer and enjoyment.

The replication of the proposed model with consumers with different profiles and from other cultural clusters would be relevant to validate and expand the scope of the results; what seems to be irrelevant to one group may be considered highly relevant to another. Results found here apply to young Brazilian consumers only, and it is possible that different groups will display different perceptions about mobility, contextual offer and enjoyment than those found in this study. Future research should explore other scales for the employed constructs or try other constructs that are conceptually similar, comparing results with those obtained here. Separating trust in each of its dimensions and analyzing how each dimension is affected by any determinants of trust in general could also provide in-depth views of trust dimensions' internal balance and formation. Literature indicates that social networking seems to be a major contributor to online trust, and mobile device users seem to make intense use of social networking via their devices. Perhaps social networking constructs, such as word-of-mouth, play as an important part in building trust in mobile environments as they do in building online trust. A controlled experiment using specific service providers and brands could be applied to elucidate their influence on the constructs tested. Finally, it would be interesting to investigate possible moderating effects of certain demographic variables (e.g. gender, income, age).

\section{References}

Ballester, E. D., \& Espallardo, M. H. (2008). Effect of brand associations on consumer reactions to unknown on-line brands. International Journal of Electronic Commerce, 12(3), 88-113. doi: 10.2753/JEC1086-4415120305

Bart, Y., Shankar, V., Sultan, F., \& Urban, G. L. (2005). Are the drivers and role of online trust the same for all web sites and consumers? A large-scale exploratory empirical study. Journal of Marketing, 69(4), 133-152. doi: 10.1509/jmkg.2005.69.4.133

Beldad, A., de Jong, M., \& Steehouder, M. (2010). How shall I trust the faceless and the intangible? A literature review on the antecedents of online trust. Computers in Human Behavior, 26(5), 857869. doi: 10.1016/j.chb.2010.03.013

Boyd, J. (2003). The rhetorical construction of trust online. Communication Theory, 13(4), 392-410. doi: 10.1111/j.1468-2885.2003.tb00298.x

Byrne, B. M. (2010). Structural equation modeling with AMOS: basic concepts, applications and programming. NY: Routledge.

Camponovo, G., Pigneur, Y., Rangone, A., \& Renga, F. (2005, July). Mobile customer relationship management: an explorative investigation of the Italian consumer market. Proceedings of the International Conference on Mobile Business, Sydney, Australia, 4. 
Chung, J., \& Tan, F. B. (2004). Antecedents of perceived playfulness: an exploratory study on user acceptance of general information-searching websites. Information and Management, 41(7), 869-881. doi: 10.1016/j.im.2003.08.016

Cohen, J. B., \& Basu, K. (1987). Alternative models of categorization: toward a contingent processing framework. Journal of Consumer Research, 13(4), 455-472.

Davis, F. D. (1989). Perceived usefulness, perceived ease of use, and user acceptance of information technology. MIS Quaterly, 13(3), 319-340.

Dimitriadis, S., \& Kyrezis, N. (2010). Linking trust to use intention for technology-enabled bank channels: the role of trusting intentions. Psychology and Marketing, 27(8), 799-820. doi: $10.1002 /$ mar.20358

Doney, P. M., Cannon, J. P., \& Mullen, M. R. (1998). Understanding the influence of national culture on the development of trust. The Academy of Management Review, 23(3), 601-620. doi: 10.5465/AMR.1998.926629

Figge, S. (2004). Situation-dependent services-a challenge for mobile network operators. Journal of Business Research, 57(12), 1416-1422. doi: 10.1016/S0148-2963(02)00431-9

Fishbein, M., \& Ajzen, I. (1975). Beliefs, attitude, intention and behavior: an introduction to theory and research. Reading, MA: Addison-Wesley.

Fornell, C., \& Larcker, D. F. (1981). Evaluating structural equation models with unobservable variables and measurement error. Journal of Marketing Research, 18(1), 39-50.

Gao, T., Rohm, A. J., Sultan, F., \& Huang, S. (2012). Antecedents of consumer attitudes toward mobile marketing: a comparative study of youth markets in the United States and China. Thunderbird International Business Review, 54(2), 211-224. doi: 10.1002/tie.21452

Garbarino, E., \& Johnson, M. S. (1999). The different roles of satisfaction, trust, and commitment in customer relationships. Journal of Marketing, 63(2), 70-87.

Gefen, D. (2000). E-commerce: the role of familiarity and trust. Omega, 28(6), 725-737. doi: $10.1016 / \mathrm{S} 0305-0483(00) 00021-9$

Goodman, L. A. (1961). Snowball sampling. The Annals of Mathematical Statistics, 32(1), 148-170.

Hahn, K. H., \& Kim, J. (2009). The effect of offline brand trust and perceived internet confidence on online shopping intention in the integrated multi-channel context. International Journal of Retail and Distribution Management, 37(2), 126-141. doi: 10.1108/09590550910934272

Hair, J. F., Black, W. C., Babin, B. J., \& Anderson, R. E. (2010). Multivariate data analysis. Upper Saddle River: Prentice-Hall.

Hoffman, D. L., Novak, T. P., \& Peralta, M. (1999). Building consumer trust online. Communications of the ACM, 42(4), 80-85. doi: 10.1145/299157.299175

Hu, L. T., \& Bentler, P. M. (1999). Cutoff criteria for fit indexes in covariance structure analysis: conventional criteria versus new alternatives. Structural Equation Modeling: A Multidisciplinary Journal, 6(1), 1-55. doi: 10.1080/10705519909540118

Hwang, Y., \& Kim, D. J. (2007). Customer self-service systems: the effects of perceived web quality with service contents on enjoyment, anxiety and e-trust. Decision Support Systems, 43(3), 746760. doi: 10.1016/j.dss.2006.12.008 
Khalifa, M., \& Shen, K. N. (2008). Explaining the adoption of transactional B2C mobile commerce. Journal of Enterprise Information Management, 21(2), 110-124. doi: $10.1108 / 17410390810851372$

Kim, C., Mirusmonov, M., \& Lee, I. (2010). An empirical examination of factors influencing the intention to use mobile payment. Computers in Human Behavior, 26(3), 310-322. doi: 10.1016/j.chb.2009.10.013

Kim, D. J., Ferrin, D. L., \& Rao H. R. (2008). A trust-based consumer decision-making model in electronic commerce; the role of trust, perceived risk, and their antecedents. Decision Support Systems, 44(2), 544-564. doi: 10.1016/j.dss.2007.07.001

Kim, D. J., Ferrin, D. L., \& Rao, H. R. (2009). Trust and satisfaction, two stepping stones for successful e-commerce relationships. Information Systems Research, 20(2), 237-257.

Kim, H., Kim, J., Lee, Y., Chae, M., \& Choi, Y. (2002, January). An empirical study of the use contexts and usability problems in mobile internet. Proceedings of the Hawaii International Conference on System Sciences, Waikoloa, Hawaii, USA, 35.

Kuan, H-H., \& Bock, G-W. (2007). Trust transference in brick and click retailers: an investigation of the before-online-visit phase. Information and Management, 44(2), 175-187. doi: 10.1016/j.im.2006.12.002

Kulviwat, S., Bruner, G. C., II, Kumar, A., Nasco, S. A., \& Clark, T. (2007). Toward a unified theory of consumer acceptance technology. Psychology and Marketing, 24(12), 1059-1084. doi: 10.1002/mar.20196

Lee, M. S. Y., McGoldrick, P. J., Keeling, K. A., \& Doherty, J. (2003). Using ZMET to explore barriers to the adoption of $3 \mathrm{G}$ mobile banking services. International Journal of Retail and Distribution Management, 31(6), 340-348. doi: 10.1108/09590550310476079

Lee, S., Ha, S., \& Widdows, R. (2011). Consumer responses to high-technology products: Product attributes, cognition, and emotions. Journal of Business Research, 64(11), 1195-1200. doi: 10.1016/j.jbusres.2011.06.022

Lee, T. (2005). The impact of perceptions of interactivity on customer trust and transaction intentions in mobile commerce. Journal of Electronic Commerce Research, 6(3), 165-181.

Lee, T., \& Jun, J. (2007). Contextual perceived value? Investigating the role of contextual marketing for customer relationship management in a mobile commerce context. Business Process Management Journal, 13(6), 798-814. doi: 10.1108/14637150710834569

Lin, J., Lu, Y., Wang, B., \& Wei, K. K. (2011). The role of inter-channel trust transfer in establishing mobile commerce trust. Electronic Commerce Research and Applications, 10(6), 615-625. doi: 10.1016/j.elerap.2011.07.008

Lu, Y., Yang, S., Chau, P. Y., \& Cao, Y. (2011). Dynamics between the trust transfer process and intention to use mobile payment services: a cross environment perspective. Information \& Management, 48(8), 393-403. doi: 10.1016/j.im.2011.09.006

Mayer, R. C., Davis, J. H., \& Schoorman, F. D. (1995). An integrative model of organizational trust. Academy of Management Review, 20(3), 709-734. doi: 10.5465/AMR.1995.9508080335

McKnight, D. H., Choudhury, V., \& Kacmar, C. (2002). Developing and validating trust measures for e-commerce: an integrative typology. Information Systems Research, 13(3), 334-359.

Morgan, R. M., \& Hunt, S. D. (1994). The commitment-trust theory of relationship marketing. Journal of Marketing, 58(3), 20-38. doi: 10.2307/1252308 
Nunnally, J. C., \& Bernstein, I. H. (1994). Psychometric theory. New York: McGraw-Hill Humanities/Social Sciences/Languages.

Nysveen, H., Pedersen, P. E., \& Thorbjørnsen, H. (2005). Intentions to use mobile services: antecedents and cross-service comparisons. Journal of the Academy of Marketing Science, 33(3), 330-346. doi: 10.1177/0092070305276149

Podsakoff, P. M., \& Organ, D. W. (1986). Self-reports in organizational research: problems and prospects. Journal of Management, 12(4), 531-544. doi: 10.1177/014920638601200408

Rogers, E. M. (2003). The diffusion of innovation. New York: Free Press.

Rousseau, D. M., Sitkin, S. B., Burt, R. S., \& Camerer, C. (1998). Not so different after all: a crossdiscipline view of trust. Academy of Management Review, 23(3), 393-404. doi: 10.5465/AMR.1998.926617

Shankar, V., \& Balasubramanian, S. (2009). Mobile marketing: synthesis and prognosis. Journal of Interactive Marketing, 23(2), 118-129. doi: 10.1016/j.intmar.2009.02.002

Shankar, V., Urban, G. L., \& Sultan, F. (2002). Online trust: a stakeholder perspective, concepts, implications, and future directions. The Journal of Strategic Information Systems, 11(3-4), 325344. doi: 10.1016/S0963-8687(02)00022-7

Shankar, V., Venkatesh, A., Hofacker, C., \& Naik, P. (2010). Mobile marketing in the retailing environment: current insights and future research avenues. Journal of Interactive Marketing, 24(2), 111-120. doi: 10.1016/j.intmar.2010.02.006

Siau, K., Lim, E-P., \& Shen, Z. (2001). Mobile commerce: promises, challenges, and research agenda. Journal of Database Management, 12(3), 4-13. doi: 10.4018/jdm.2001070101

Siau, K., \& Shen, Z. (2003). Building customer trust in mobile commerce. Communications of the ACM, 46(4), 91-94. doi: 10.1145/641205.641211

Siau, K., Sheng, S., Nah, F., \& Davis, S. (2004). A qualitative investigation on consumer trust in mobile commerce. International Journal of Electronic Business, 2(3), 283-300.

Stewart, K. J. (2003). Trust transfer on the world wide web. Organization Science, 14(1), 5-17. doi: 10.1287/orsc.14.1.5.12810

Stewart, K. J. (2006). How hypertext links influence consumer perceptions to build and degrade trust online. Journal of Management Information Systems, 23(1), 183-210. doi: 10.2753/MIS07421222230106

Urban, G. L., Amyx, C., \& Lorenzon, A. (2009). Online trust: state of the art, new frontiers, and research potential. Journal of Interactive Marketing, 23(2), 179-190. doi: 10.1016/j.intmar.2009.03.001

Varnali, K., \& Toker, A. (2010). Mobile marketing research: the-state-of-the-art. International Journal of Information Management, 30(2), 144-151. doi: 10.1016/j.ijinfomgt.2009.08.009

Venkatesh, V., \& Davis, F. D. (2000). A theoretical extension of the technology acceptance model: four longitudinal field studies. Management Science, 46(2), 186-204. doi: 10.1287/mnsc.46.2.186.11926

Wang, H-Y., \& Wang, S-H. (2010). User acceptance of mobile internet based on the unified theory of acceptance and use of technology: investigating the determinants and gender differences. Social Behavior and Personality, 38(3), 415-426. doi: 10.2224/sbp.2010.38.3.415 
Zhang, J., \& Mao, E. (2008). Understanding the acceptance of mobile SMS advertising among Young Chinese consumers. Psychology and Marketing, 25(8), 787-805. doi: 10.1002/mar.20239

Zhang, L., Zhu, J., \& Liu, Q. (2012). A meta-analysis of mobile commerce adoption and the moderating effect of culture. Computers in Human Behavior, 28(5), 1902-1911. doi: 10.1016/j.chb.2012.05.008

Zhou, T. (2011). An empirical examination of initial trust in mobile bank. Internet Research, 21(5), 527-540. doi: 10.1108/10662241111176353

\section{Authors' Profiles}

Cristiane Junqueira Giovannini

Rua Marquês de São Vicente, 225, Gávea, 22451-900, Rio de Janeiro, RJ, Brazil. E-mail address: mestrekis@ gmail.com

Jorge Brantes Ferreira

Rua Marquês de São Vicente, 225, Gávea, 22451-900, Rio de Janeiro, RJ, Brazil. E-mail address: jorge.brantes@ gmail.com

Jorge Ferreira da Silva

Rua Marquês de São Vicente, 225, Gávea, 22451-900, Rio de Janeiro, RJ, Brazil. E-mail address: jorge1319@ gmail.com

Daniel Brantes Ferreira

Av. Presidente Wilson, 118, 20030-020, Rio de Janeiro, RJ, Brazil. E-mail address: daniel.brantes@gmail.com 


\section{APPENDIX}

\section{Measurement Scales}

Intention to Use (Khalifa \& Shen, 2008) - CR $=0.94, \mathrm{AVE}=0.75$

"I intend to conduct m-commerce transactions in the near future".

"It is likely that I will use m-commerce in the near future".

"I expect to use m-commerce services in the near future".

Perceived Ease of Use (Nysveen, Pedersen, \& Thorbjornsen, 2005) $-\mathrm{CR}=0.90, \mathrm{AVE}=0.66$

"Learning to use m-commerce is easy to me".

"It is easy to make a m-commerce service do what I want it to".

"My interaction with m-commerce services is clear and understandable".

"It is easy to use m-commerce".

Perceived Enjoyment (Nysvenn et al., 2005) $-\mathrm{CR}=0.95, \mathrm{AVE}=0.83$

"I find m-commerce entertaining".

"I find m-commerce pleasant".

"I find m-commerce exciting".

"I find m-commerce fun".

Perceived Contextual Offer (Lee, 2005) $-\mathrm{CR}=0.87, \mathrm{AVE}=0.70$

"Mobile commerce services offer timely packets of information (e.g. restaurant coupon for lunch) to me".

"Mobile commerce services provide me with location-specific packets of information (e.g. sale information when I enter the department store)".

"Mobile commerce services provide me with optimal information or service that is contextually relevant to me based upon where I am and what I am interested".

Attitude toward using m-commerce (T. Lee, 2005) $-\mathrm{CR}=0.89, \mathrm{AVE}=0.70$

"Using mobile services to purchase is a good idea".

"Using mobile services to purchase is a wise idea".

"Using mobile services to purchase is an appealing idea".

Perceived Mobility (Kim, Mirusmonov, \& Lee, 2010) $-\mathrm{CR}=0.88$, AVE $=0.60$

"I believe m-commerce is independent of time".

"I believe m-commerce is independent of place".

"I can use m-commerce anytime while traveling".

Perceived Usefulness (Kim et al., 2010) $-\mathrm{CR}=0.92$, AVE $=0.69$

"Using m-commerce would enable me to purchase more quickly".

"Using m-commerce makes it easier for me to conduct transactions".

"I would find m-commerce a useful possibility for purchasing goods and services". 
Brick-and-Mortar Trust (Kuan \& Bock, 2007) $-\mathrm{CR}=0.80, \mathrm{AVE}=0.60$

"Regular stores would act in my best interest".

"Regular stores would keep their commitments to me".

"Regular stores would have the ability to meet most of my needs as a customer".

Online Trust (Kuan \& Bock, 2007) $-\mathrm{CR}=0.80, \mathrm{AVE}=0.60$

"Online stores would act in my best interest".

"Online stores would keep their commitments to me".

"Online stores would have the ability to meet most of my needs as a customer".

Mobile Trust (Kuan \& Bock, 2007) $-\mathrm{CR}=0.85, \mathrm{AVE}=0.66$

"Mobile sites and apps would act in my best interest".

"Mobile sites and apps would keep their commitments to me".

"Mobile sites and apps would have the ability to meet most of my needs as a customer". 